\title{
Perceptions of Partner Risk and Influences on Sexual Decision-Making for HIV Prevention among Students at Historically Black Colleges and Universities
}

\author{
Melva V. Thompson-Robinson, Donna L. Richter, Marya L. Shegog, Mike \\ Weaver, Leah Trahan, Denethia B. Sellers, and Vanisha L. Brown
}

\begin{abstract}
Rates of HIV/AIDS are rising on the campuses of Historically Black Colleges and Universities (HBCUs). This paper examines the extent of these students' knowledge of their sexual partners' HIV risk behaviors and how their decision-making regarding sexual activity is shaped by this knowledge or lack of knowledge. Six focus groups were conducted with African American men and women attending HBCUs in the southeastern US. Commonality and divergence exist on the influences on African American male and female students' HIV risk taking behaviors, including media, community, family, and religion. Participants in these focus groups indicated that engaging in discussions about HIV/AIDS could be detrimental to their relationships. The reluctance to engage in discussions about HIV/AIDS offers compelling evidence of the need to enhance the communication and negotiation skills of these students in order to reduce barriers to safer sex.
\end{abstract}

\section{INTRODUCTION}

HIV/AIDS has been a particularly delicate subject since its emergence more than two decades ago. Once believed to be a disease of gay, Caucasian males, HIV has exploded within American culture and has adversely impacted all segments of society. The number of individuals living with AIDS significantly increased be-

\footnotetext{
Melva V. Thompson-Robinson is an assistant professor in the Department of Health Promotion, School of Public Health, University of Nevada, Las Vegas. Donna L. Richter, Marya L. Shegog, Mike Weaver, and Leah Trahan work at the Department of Health Promotion, Education, and Behavior, Arnold School of Public Health, University of South Carolina, Columbia. Denethia B. Sellers and Vanisha L. Brown are affiliated with the Department of Health, Physical Education, and Recreation, College of Education, Florida A\&M University.
}

Journal of African American Studies, Fall 2005, Vol. 9, No. 2, pp. 16-28. 
tween 1992 and 1999, due to the expansion of the AIDS case definition in 1993, as well as benefits from new combination drug therapies (CDC, 2002).

Currently, 800,000 to 900,000 people are estimated to be living with HIV in the United States. It is expected that approximately 40,000 new cases of HIV will be diagnosed in 2005. African American men and women will represent 50\% and $64 \%$ of these new cases respectively (CDC, n.d.).

According to CDC data for 1999-2002, the primary mode of exposure to HIV in the 29 states with name-based HIV reporting is heterosexual contact $(35 \%$ of new infections). Among women, $64 \%$ of the new infections are acquired through heterosexual contact (CDC, 2004). Among African Americans, 64\% of new cases in women and $36 \%$ of new cases in men were attributed to heterosexual contact between 1999 and 2002 (CDC, 2004). Even when women do not report risk information at the time of testing, more than two-thirds of cases are later classified as heterosexual contact (CDC, 2002).

A further contribution to the impact of HIV/AIDS is the issue of men who have sex with men but do not disclose their sexual orientation. Minority men who sleep with men often fail to disclose their sexual orientation because of fear of social isolation, discrimination, or verbal/physical abuse. In a study of 637 men who did not disclose their sexual orientation, $8 \%$ were HIV infected (CDC, 2003). Sixtyone percent of non-disclosing African American men reported engaging in unprotected sex with their female sex partners. These men also reported perceiving themselves to be at low risk for becoming infected with HIV (CDC, 2003).

It is expected that the HIV/AIDS epidemic in the Southeastern United States will have a dramatic effect on a large proportion of individuals ages 20-45 during their most productive years (Southern States AIDS/STD Directors Work Group, 2003). It has been projected that young African Americans of college age will be the next group to be affected by the HIV/AIDS epidemic (Duncan et al., 2002). African American college students have a significantly higher rate of heterosexual transmission of HIV than the general population (Duncan et al., 2002).

A recent HIV outbreak among college students, was uncovered by the North Carolina HIV Ribonucleic Acid (RNA) screening program, entitled Screening Tracing Active Transmission program (STAT) (Multicampus outbreak in HIV in North Carolina spurs quick state action, 2003). The outbreak occurred at 11 predominately black colleges and one Native American college among young black males who have sex with other males (MSM). As a result of the program, researchers were able to identify 146 newly infected men in North Carolina. Twenty-five of these men attended 11 colleges in North Carolina (Multicampus outbreak in HIV in North Carolina spurs quick state action, 2003) and were linked to a sexual network involving seven additional campuses located in Georgia, Florida, South Carolina, Virginia, West Virginia and the District of Columbia (Black colleges seek to stem HIV cases, 2004). Eighty-eight percent of the 25 men attending the 11 North Carolina colleges were African American and the same percentage was also MSM.

In response to this study, Lisa Fitzpatrick, a medical epidemiologist at the Centers for Disease Control and Prevention, stated, "another reason this investigation is important is because it will highlight the critical need of health resources in the South" (Multicampus outbreak in HIV in North Carolina spurs quick state action, 2003). These findings have prompted the state of North Carolina and the affected 
colleges to collaborate on an initiative that will provide education and training for HIV counseling and testing (Multicampus outbreak in HIV in North Carolina spurs quick state action, 2003).

Research related to HIV risks among African American college students and among students in Historically Black Colleges and Universities (HBCUs), in particular, has produced varied results. In research conducted with African American college students, Foreman (2003) found that women tended to use philosophical and emotional strategies as well as regard for the level of commitment in their sexual relationship to determine their safer sex behavior.

Valentine, Wright and Henly (2003) found that allied health students at HBCUs tended to be more mature, knowledgeable, and likely to engage in safer sex practices in comparison to other students in their sample. They also discovered that condom usage was higher among African American students compared to students of other racial and ethnic groups. Bazargan, Kelly, Stein, Husaini, and Bazargan (2000) found that providing behavioral skills for negotiating safer sex and training in the proper use of condoms are key elements to reducing high risk behaviors among students at HBCUs.

This project utilizes focus group methodology to gather data from African American men and women who attend HBCUs in South Carolina and Georgia to ascertain their perspectives related to HIV/AIDS. Specifically, this research seeks to examine how these perspectives are influenced by knowledge, culture, gender, communication, and participation in risky sexual behaviors.

\section{METHODS}

Six focus groups were conducted with a total of 54 African American men and women ages 18-22 who currently attend HBCUs in South Carolina and Georgia. The participants were recruited and selected through a campus contact person and the utilization of a demographic screening questionnaire. Training culturally appropriate focus groups moderators, who were also members of the research team, facilitated and took notes at each of the discussions. The focus group discussion guide consisted of ten open ended questions targeted to illicit discourse that address the research questions. All focus groups were audio taped and recordings were professionally transcribed for analysis. See Table 1 for the questions asked in each focus group. All focus groups were audio taped and recordings were professionally transcribed verbatim. Notes were also taken during the focus groups.

NVivo 2.1, a software package for coding and analysis of textual data, was used to analyze the transcripts from all of the focus groups. The research team developed a codebook with definitions that were used as a guide for coding data in the transcripts. Two members of the research team then coded each transcript. Members of the research team met to review the coded transcripts and reconciled any differences in coding through comparison and discussion. Revisions to the codebook were made and applied to the coding of all transcripts.

Emergent themes were identified from the data across all focus groups as well from focus groups with just male participants or with just female participants. To be considered a theme, a topic had to occur across all focus groups (or all female groups or all male groups) and had to be mentioned more than once in each focus group. 
Table 1

Focus Group Questions
1. When you hear the term "HIV risk" what comes to mind?
2. How comfortable do you think African American men/women as a whole are in communicating with their partners about HIV?
3. How comfortable do you think African American women/men as a whole are in communicating with their partners about HIV?
4. Describe how a discussion of HIV risk with your partner would go?
5. Even if he knows the risks, describe the reasons why you think an African American $\mathrm{man} /$ woman might continue to have unprotected sex with a woman/man who is at high risk for HIV?
6. How do you think culture influences African American men's/women's decisions about sexuality and sexual practices?
7. How do you think culture influences African American women's/men's decisions about sexuality and sexual practices?
8. How comfortable do you think African American men/women would feel discussing this topic in a group setting?
9. What words should be used to describe sexual practices and behaviors?
10. What suggestions do you have on how to encourage these men/women to participate?

\section{RESULTS}

The questions that were utilized in the focus groups (Table 1) were designed to gather information about the participants' perceptions of HIV/AIDS and their knowledge and insight into HIV risk resulting from heterosexual relationships among African American students at HBCUs. Themes that emerged from the data are grouped into three categories:

1. general HIV knowledge and transmission,

2. communication between sexual partners concerning HIV,

3. sexual perceptions and the decision to be sexually active.

Table 2 identifies the themes in each of the categories and indicates whether the theme emerged in discussions with males only, females only, or both.

\section{THEMES CONCERNING HIV KNOWLEDGE AND TRANSMISSION}

Students in the focus groups were asked, "When you hear the term HIV risk what comes to mind?"

\section{Theme: Familiarity with General HIV Knowledge}

The students on HBCU campuses in this study were aware of HIV and of the common routes of transmission of HIV. Examples of the comments from the students are:

- "You can't get AIDS from somebody blowing their breath. You get it through open wounds or unprotected sex. Anything of that sort." 
Table 2

Themes by Gender

\begin{tabular}{|c|c|c|}
\hline Category & $\begin{array}{c}\text { HBCU } \\
\text { Male } \\
\text { Students }\end{array}$ & $\begin{array}{l}\text { HBCU } \\
\text { Female } \\
\text { Students }\end{array}$ \\
\hline \multicolumn{3}{|l|}{ General HIV knowledge and transmission } \\
\hline Students are familiar with modes of HIV transmission & $\mathbf{X}$ & $\mathbf{X}$ \\
\hline Students are aware of increasing rates heterosexual transmission & & $\mathbf{X}$ \\
\hline \multicolumn{3}{|l|}{ Communication between sexual partners about HIV } \\
\hline HIV not a consideration in sexual decisions & $\mathbf{X}$ & \\
\hline Lack of HIV knowledge as barrier to communicate about HIV to partner & & $\mathbf{X}$ \\
\hline Fear of loss of relationship as an outcome HIV discussion & & $\mathbf{X}$ \\
\hline $\begin{array}{l}\text { Females' trust in their sexual partner(s) results in no need to have a } \\
\text { HIV discussion }\end{array}$ & & $\mathbf{X}$ \\
\hline Women should be the initiators of HIV discussion & $\mathbf{X}$ & $\mathbf{X}$ \\
\hline Men would be the initiators of HIV discussion & $\mathbf{X}$ & \\
\hline HIV discussions occur after having sexual relations & $\mathbf{X}$ & \\
\hline $\begin{array}{l}\text { HIV discussion should occur early in a relationship, prior to beginning } \\
\text { sexual activity }\end{array}$ & $\mathbf{X}$ & $\mathbf{X}$ \\
\hline \multicolumn{3}{|l|}{ Reasons for having unprotected sex } \\
\hline Females have unprotected sex as an expression of love for partner & $\mathbf{X}$ & $\mathbf{X}$ \\
\hline $\begin{array}{l}\text { The physical appearance of partner will encourage persons to have } \\
\text { unprotected sex }\end{array}$ & $\mathbf{X}$ & \\
\hline $\begin{array}{l}\text { Females sometimes have unprotected sex in exchange for money or } \\
\text { material gain }\end{array}$ & & $\mathbf{X}$ \\
\hline \multicolumn{3}{|l|}{ Influence that delay sexual activity } \\
\hline Family/parental influences on college student delaying sexual activity & $\mathbf{X}$ & $\mathbf{X}$ \\
\hline Religious doctrine influences decision to have sex & $\mathbf{X}$ & $\mathbf{X}$ \\
\hline Perception that females more closely adhere to religious doctrine & $\mathbf{X}$ & \\
\hline \multicolumn{3}{|l|}{ Influences that encourage sexual activity } \\
\hline Peer and community pressures & $\mathbf{X}$ & \\
\hline Media's portrayal of sexual activity & $\mathbf{X}$ & $\mathbf{X}$ \\
\hline Hip hop influences students' beliefs and attitudes about sex & $\mathbf{X}$ & $\mathbf{X}$ \\
\hline Rappers greatly impact men's sexual actions and perceptions & & $\mathbf{X}$ \\
\hline Music videos impact women's dress and sexual activity & $\mathbf{X}$ & \\
\hline Lack of consistency in media perceptions about HIV and sex & & $\mathbf{X}$ \\
\hline
\end{tabular}

- "Unprotected sex" (group response).

- "There's different ways you can get it like sharing needles among other things like having oral sex and stuff."

Overall the students were aware of HIV/AIDS in their college community and understood that if they participated in acts that placed them at risk, HIV was one of the possible consequences. 


\section{Theme: Males Seen as Spreading HIV}

Female students were aware that HIV is not uncommon among their peers. They also noted that they can be infected by male partners, as indicated in the following quote from a female student:

"A lot of our generation, ... between 18 and 24 are a lot of people who have it now and its mostly carried from ... a lot of males."

The male students further elaborated on the theme of males spreading HIV to their female sexual partners, through the idea that males are willing to participate in sexual acts for the sake of pleasure regardless of the consequences.

"Guys will have unprotected sex period. Regardless, she could get pregnant. Those are risks that men take anyway. You don't think about that she's at high risk to get AIDS and pregnancy. Guys think, like, 'I'm just about to get mine.' It's a whole list of consequences that could happen afterwards that you don't even think about."

\section{THEMES CONCERNING COMMUNICATION ABOUT HIV BETWEEN MALE AND FEMALE PARTNERS}

Students in the focus groups were asked how a conversation between partners about HIV risk would be conducted. The students were further probed about who would initiate the conversation, the comfort level of the participants in the conversation and what would be the final outcome of such a conversation.

\section{Theme: Lack of Knowledge about HIV}

Despite indicating that they knew about modes of transmission (see above), female students cited lack of sufficient information about HIV as a possible reason for not having a conversation about risk with a sexual partner.

- "There are a lot of African American women, not only women but men, who don't know a lot about AIDS so they really can't talk about this with their partner because they don't know much about it."

\section{Theme: Fear of Loss of Relationship}

Communication about HIV in the college setting is particularly difficult due to fear of the consequences of having such a discussion. Female students indicated feeling uncomfortable discussing issues related to HIV/AIDS with their partners because they feared they would lose the intimate relationship with their partners as a result of such discussions.

- "Some females . . . they think that if they come out and say something about it they might offend their partner." 


\section{Theme: Female Trust of Male Partner}

The female students also indicated that in a relationship they have a tendency to trust their partners and may feel as though a discussion about HIV/AIDS is not necessary.

- "Women [are] feeling like they can trust their partners or just having their mind on some other things other than HIV risk not even thinking about it."

- "So they feel they can trust that partner so they really don't bring it up."

\section{Theme: Women as Initiators of HIV Discussion}

Many of the male students that participated in the focus groups indicated that they had initiated a conversation about HIV and HIV testing with their potential partners.

- "I'm kind of a blunt person. I'm just gonna go ahead and get out of the way. I tell her look, "I get tested. How about you? Do you get tested?"

More often, however, they agreed that women were the ones who broached the subject of HIV with their partners and that women were more comfortable in doing so than were men.

- "If we're getting ready to have sex, maybe not physically but within the week or next couple of days and we both know it, she'll come out and ask, "Have you even been tested?"

- "I think women are more comfortable and would bring it up more often than men. They're more careful, too. In a lot of cases, women go to the doctor more often than men. They wanna be extra careful and more protective. So, I think they're much more comfortable than men."

Overall, both the male and female students felt that women were more often the initiators of a discussion concerning issues related to HIV/AIDS, despite their concerns about having such a conversation.

\section{Theme: Belated Timing of HIV Discussion}

In many cases, the male students indicated that the conversation about HIV was initiated only after the couple had already engaged in sexual intercourse.

- 'It's usually after we've had sex and she'll ask [about HIV testing]. I let 'em know I have. But from my experience, they have asked. "

- "I never had the conversation beforehand ... the only time I ever had it was afterwards. It was months afterwards, later along in the relationship after we'd been having sex ... It could have been more volatile earlier in our relationship. After a while, you gotta have that conversation."

Both male and female participants stated that, ideally, issues related to HIV should be discussed openly in the early stages of the relationship. One male participant stated: 
- "I really think that should be one of the conversations in a relationship. One of the first things, because, I mean, you can't tell who has it just by looking at them."

\section{THEMES CONCERNING REASONS FOR HAVING UNPROTECTED SEX WITH A PARTNER WHO MAY BE AT HIGH RISK FOR HIV}

\section{Theme: Love and the Perception of Love as Reasons to Have Unprotected Sex}

While discussing reasons why people may choose to have unprotected sex with a partner who may be at high risk for HIV, across all focus groups participants indicated that the feeling of being in love resulted in unsafe sexual practices. The female students indicated that one of the most predominant reasons why women choose to have sex with a high-risk male is love.

- "That's one reason that she might continue to have sex with a man that she thinks is a high risk would be because she says she loves him."

- "[S]he gives him this [sex] without using protection, he'll be there for her and love her."

Some of the male students also indicated that often women believe that having unprotected sex with a high risk male is an expression of his love for her.

- "They thinking we love them, and we just trying to get our nut off [ejaculate]. And feel good at the same time."

- "She's feeling like this, "He ain't using no condom on me, he must love me."

The male participants indicated that women and men have sex for different reasons and that men often utilize the women's need for love to have unprotected sex.

- "In my eyes, it's a difference between why men have sex and why a lot of women have sex. A lot of men can have sex cause they see a female and she got a nice booty. She might have a nice face. It might be a lot of different reasons."

- "All we [men] do, our whole mission, every hour, is to get up on it [have sex]. But their whole mission is to find a mate."

- "She might be in love or something. He might be cheating on her."

- "I think a lot of guys are manipulative. You make a girl think you care about her or you feel for her, she'll automatically do it [have unprotected sex]."

- "A lot of girls do be in love. If a girl loves you and she knows you doing wrong, she willing to do anything for you."

\section{Theme: Material Gain as a Reason to Have Unprotected Sex}

The female participants also indicated that some women may maintain unsafe sexual practices for the sake of material gain. This idea was not reflected in the male focus groups. Comments the female students made about having sex for money indicated that they felt the practice was inappropriate behavior.

"Some girls are so grimy that they just do it for the money." 


\section{THEMES CONCERNING SEXUAL PERCEPTIONS AND THE DECISION TO BE SEXUALLY ACTIVE}

The genesis of sexual activity often occurs during the college experience. There are many factors that contribute to the decision of males and females to become and remain sexually active. The participants in all the focus groups were asked to discuss the major forces of influence for themselves as well as for the opposite sex.

\section{Theme: Family Support and Childhood Lessons as Influencers of Sexual Decisions and Behavior}

Throughout all the focus groups, the importance of family and parental influence was discussed as a key factor in shaping the students sexual behavior. The women indicated that parents and family expectations shaped their morals and therefore impacted their sexual behavior.

- "So all I can say is that it all depends on what you been taught by your parents and your morals."

- "[T]here are a lot people whose parents, you know have taught them things and they've explained to them.... Like with me, my parents always say no sex before marriage."

The male students also indicated that their actions were dictated by their childhood and expectations of their families.

- "I was saying a lot of people just follow, you know, their family tradition."

\section{Theme: Religious Doctrine and Affiliations Help to Shape the Sexual Lives of African American Students}

Both the male and female participants recognized the role of spiritual teachings in their lives and how these teachings may influence their decisions to have sex or to maintain sexual relationships.

- "With Christianity, with all the Bible saying no sex before marriage, ... and then with the whole thing about wearing a white dress when you are married to show that you're pure, that may have a big influence too."

- "I think religion has a lot to do with it because I'm saying if you're true to your religion and your religion say don't do that, you ain't gonna do it. ..."

The male students further perceived that women more closely adhere to religious teaching and allow religious principles to influence their sexual decisions.

- "If your family was brought up in the church, like the girls in the church were supposed to be a lady. Never doing bad things."

- "They're [women]) more spiritual. They go to church all the time. They try to live by the Word." 
Theme: Peers and the Community Play a Role in Shaping African American Men's Sexual Perceptions and Behavior

African American men reported that their community and male peers had a great influence upon their sexual decisions and actions.

- "I think you're a product of your environment. It's how you grew up ... the older dudes in the neighborhood. They saying, "Hey, man, I'm hitting it raw." ... You growing up and that's what you learned and was taught. You think, well, hell, that's what you're supposed to do. . . . They just gonna go off the way they heard growing up in their environment."

- "I think peer pressure has a lot to do with it. ..."

- "I think it's peer-led. When guys talk about their sexual partners, you don't say that you talked about AIDS or did you use a condom. They talk about how it went down. It's like celebrating the conquest. You come back and tell the fellas."

\section{Theme: Significant Impact of Media on Sexual Perceptions and Decisions}

The female students that participated in the focus groups indicated that all the students are greatly influenced by media.

- "[P]eople actually do what they see on TV. A lot of people are run by what they see on TV or what they hear on the radio...."

The male students indicated that media equally influences both women and men.

- "What I see and what I live and what's going on in the media, it seems like the thing to do is to be promiscuous as a male. To have as many sexual partners as possible, having more partners put you at risk. So the media goes with making you take more risk."

- "The way the culture has become in a sense because you do watch BET and MTV, you see all these females in these videos shaking their asses. It definitely has an affect on your whole psyche."

- "Media, all that TV plays a part into it. Every time you turn around, you always see sex. Movies be killing people. When you see love scenes, you don't see too many people using protected sex. You don't never see condoms a lot of times."

Both the male and female students recognized the influence of the hip-hop culture on their perceptions about sex and sexual practices. The female participants indicated that they believe men to be greatly influenced by the rap personalities.

- "I think a lot of men. They look up at the rappers on TV..."

The male students expressed their perception that women are greatly influenced by the roles of women in music videos.

- "Women are more impressionable by the media. They're more easily susceptible to what they see, like in the videos." 
- "Culture may cause women to be more promiscuous. Media has the women to dress like sluts kind of."

\section{Theme: Conflicting Messages from Media about Sex and Sexual Practices}

The female students that participated in the study stressed their concern about the mixed messages sent by the media and how that impacts their perceptions on sex and sexual activity.

- "A lot of men and women tend to look at rappers and listen to what they say and not actually what they do... and in reality these rappers are not actually doing these things, they're just saying them to sell records."

- "Cause we all BET, MTV all day long ... So the hip-hop culture they give mixed messages. . . . cause half of these rappers is out there rapping about how they like it raw, let them beat you without a condom, but then they promote safe sex on TV."

- "But at the same time, you see shows on TV talking about how STD rates have gone up in the past year. ..."

\section{Theme: Issues Regarding Sexual Activity and Condom Use Transcend Race/ Culture/Religion}

The male students indicated that the issues facing them regarding sexual activity and condom use for HIV prevention were not specific to one race, but more attributable to the United States on a whole.

- "But again, like I say that's not just African-American culture. I mean a lot of people, all types of videos and stuff no matter what kind white or black or whatever they all show sex appeal and everybody watches soap operas."

- "But when it comes down to putting on a condom, it ain't got nothing to do with culture."

The female students further supported this idea and expanded the context to include gender and different religious affiliations.

- "I really don't think culture has anything to do with it. I think it's the same between women among any race. Everyone has the same types of peer pressure. They might not be in the same form but everybody has the same. It's all the same really the culture really has no influence on it."

- "It's not different race to race and with religion."

\section{CONCLUSION}

In addition to academic study for students, college attendance often represents a time for sexual exploration and freedom. Unfortunately, as recent reports from the campuses of HCBUs in North Carolina have shown, this sexual exploration and freedom can result in students contracting HIV. Students that participated in this study revealed that although they are aware of HIV and the risks associated with unprotected sex, there are a myriad of other factors that influence their HIV risk behaviors.

For example, expressions or understanding of love between partners in a rela- 
tionship often result in unsafe sex practices. In some cases, men will use insincere expressions of love in order to have unprotected sex with a woman. The findings of this study support previous work by Foreman (2003).

The students in this study acknowledged the influence of the media and, in particular, hip hop culture on their sex roles, decisions, and actions. According to the women in these focus groups, men tended to be primarily influenced by the words and actions of rap music stars. Men, on the other hand, felt that women were influenced by the actions and looks of women in music videos.

Religious teachings were cited as a mediator of factors influencing or promoting unsafe sex practices and decisions. Students indicated that they adhere to these teachings, which impact sexual decisions and actions. For women, in particular, these results reflect findings from Foreman (2003) in which African American female college students often utilized philosophical strategies to decide whether to engage in unsafe sex.

In examining the communication that occurs between sex partners, both men and women indicated feeling uncomfortable in talking with their partner about issues related to HIV risk. Women indicated that they may be unlikely to have this discussion because they do not feel adequately prepared to do so. These women also said that they may not initiate this discussion if they fear that the discussion will be detrimental to the relationship. In acknowledging their lack of comfort, men indicated that they have had a discussion about issues related to HIV after sexual relations with a partner have already begun.

Clearly, as found by Bazargan et al. (2000), behavioral skills for negotiating safer sex and training in proper use of condoms are not only needed but can be an effective intervention for students at HBCUs. Based on the results of this study, such an intervention should also address students' comfort in discussing issues related to HIV in relationships. Again, both men and women in this study expressed not being comfortable initiating such discussions.

This intervention also needs to acknowledge the influence of the media, hip hop culture, family, and religion. The media and hip hop culture were cited by participants as impacting unsafe sex practices and decisions. In this intervention, participants could be provided with an opportunity to explore the impact of these on their own sex practices and decisions. Family and religion, on the other hand, were brought up as promoting safer sex decisions and practices. Where possible, members of the faith community should be involved in promoting safer sex among students at HBCUs.

\section{ACKNOWLEDGEMENTS}

This project was funded by a cooperative agreement from the Centers for Disease Control and Prevention through the Association of Schools of Public Health (Grant Number: U36/CCU300430-20).

\section{REFERENCES}

Black colleges seek to stem HIV cases: stepping up safe-sex education after spike in infections. (2004, March 22). Retrieved June 2, 2004, from http://msnbc.msn.com/id/4556054. 
Multicampus outbreak of HIV in North Carolina spurs quick state action: prevention, testing program targets black colleges. (2003). AIDS Alert, 18, 149 \& 151-2.

Bazargan M., Kelly E.M., Stein J.A., Husaini B.A., \& Bazargan S.H. (2000). Correlates of HIV risk taking behaviors among HIV knowledge, motivation, and behavioral skills. Journal of the $\mathrm{Na}$ tional Medical Association, 92, 391-404.

Centers for Disease Control and Prevention (CDC). (n.d.). HIV/AIDS Update. A glance at the HIV epidemic. (Fact sheet). Atlanta, GA: Centers for Disease Control and Prevention.

Centers for Disease Control and Prevention (CDC). (2002). HIV/AIDS among U.S. women: Minority and young women at continuing risk. Atlanta, GA: Centers for Disease Control and Prevention.

Centers for Disease Control and Prevention (CDC). (2003). HIV/STD risks in young men who have sex with men who do not disclose their sexual orientation - Six U.S. cities, 1994-2000. Morbidity and Mortality Weekly Report, 52, 81-5.

Centers for Disease Control and Prevention (CDC). (2004). Heterosexual transmission of HIV -29 states, 1999-2002. Morbidity and Mortality Weekly Report, 53, 125-9.

Duncan, C., Miller, D.M., Borskey, E.J., Fomby, B., Dawson, P., \& Davis, L. (2002). Barriers to safer sex practices among African American college students. Journal of the National Medical Association, 94, 944-51.

Foreman, F.E. (2003). African American college women: Constructing a hierarchy of sexual arrangements. AIDS Care, 15, 493-504.

Southern States AIDS/STD Directors Work Group (2003). Southern states manifesto-HIV/AIDS and STDs in the south: a call to action. Washington, DC: National Alliance of State and Territorial AIDS Directors.

Valentine, P.A., Wright, D.L., \& Henly, G.L. (2003). Patterns of safer sex practices among allied health students at historically black colleges and universities. Journal of Allied Health, 32, $173-8$. 